\title{
Clinicopathological study of organ metastasis in endometrial cancer
}

\author{
Weipu Mao ${ }^{\ddagger, 1}$, Shaomin Wei ${ }^{\ddagger, 2}$, Hui Yang ${ }^{\ddagger, 3}$, Qianqian $\mathrm{Yu}^{4}$, Mei Xu' ${ }^{1}$ Jing Guo ${ }^{\star \pm,, 4}$ \& Li \\ Gao**,*,1 (D) \\ ${ }^{1}$ Department of Obstetrics \& Gynecology, The People's Hospital of Yingshang, Anhui 236200, PR China \\ ${ }^{2}$ Department of Neurology, Shanghai Tenth People's Hospital, Tongji University, Shanghai 200072, PR China \\ ${ }^{3}$ Department of General Surgery, Jiuting Hospital, Songjiang District, Shanghai 201600, PR China \\ ${ }^{4}$ Department of Obstetrics \& Gynecology, Shanghai Tenth People's Hospital, Tongji University, Shanghai 200072, PR China \\ *Author for correspondence: taocherry@sina.com \\ **Author for correspondence: Tel.: +86 13956699 169; Fax: +86 13956699 169; gaoli9169@163.com \\ $\ddagger$ Authors contributed equally
}

\begin{abstract}
Aim: Our aim was to analyze the clinicopathological features of lung, liver, bone and brain metastasis in patients with endometrial cancer (EC). Patients \& methods: We screened patients diagnosed with EC between 2010 and 2015 from the Surveillance, Epidemiology and End Results database. Results: Among 69,027 eligible EC patients, lung metastasis was the most common. Patients with lung or liver metastasis were at higher risk of bone and brain metastases than those without lung and liver metastasis. Brain metastasis has the lowest survival time (5.0 months) in single organ metastasis. Liver and brain metastasis have the highest death rate in two organ metastasis, and lung, liver and brain metastasis had the lowest survival time (1.0 month) in multi-sites metastasis. Conclusion: Lung metastasis was the most common in EC patients. Assessing distant organ metastasis may help clinicians to determine appropriate follow-up strategy for patients with EC.
\end{abstract}

First draft submitted: 7 January 2020; Accepted for publication: 26 February 2020; Published online: 9 March 2020

Keywords: endometrial cancer • metastasis • SEER • survival

Endometrial cancer (EC) is the most common carcinoma of the female reproductive tract in developed countries, and its incidence rate shows a significant upward trend [1]. In the USA, approximately 63,000 cases were newly diagnosed in 2018, making it the fourth most common cause of cancer and the seventh most common cause of death in women [2]. EC is a kind of epithelial malignant tumor which occurs in the endometrium [3]. According to its clinical features and biological behavior characteristics, the pathological types can be divided into endometrioid carcinoma and nonendometrioid carcinoma [4].

Surgery, chemotherapy and radiotherapy are the main treatments for patients with EC [5,6]. The 2009 International Federation of Gynecology and Obstetrics (FIGO) and the tumor-node-metastasis classifications are the most commonly used classifications based on surgical staging [7]. Because most patients with $\mathrm{EC}$ are in the initial diagnosis stage, the tumor is still limited to the uterine body, surgical treatment has a good prognosis [7]. Therefore, surgery is the preferred treatment of EC patients [8]. For early stage (stage I and II) EC patients, open surgery, traditional laparoscopy, robot and other surgical methods can be used to completely remove the lesions [9-11]. For advanced stage (stage III and IV) EC patients, surgical removal of cancer lesions is aimed at no residual lesion, postoperative combined radiotherapy and chemotherapy can improve the survival rate of patients [12]. EC patients (15-25\%) are advanced at the time of diagnosis, and many clinical and pathological factors affect the prognosis and survival time of EC patients, among which site of metastasis is one of the most important factors affecting survival time [2].

Lymph node metastasis is the main metastatic pathway of EC. The most common metastasis site of EC are pelvic lymph nodes, such as common iliac, internal iliac and external iliac lymph nodes [13], followed by retroperitoneal lymph nodes. Distant metastasis such as lung and brain metastasis is rare [14]. In our study, we used data from the Surveillance, Epidemiology and End Results (SEER) cancer registration database to analyze organ metastasis in EC patients diagnosed from 2010 to 2015.

Future Medicine 


\section{Patients \& methods}

\section{Database}

The SEER database is currently the largest publicly available cancer database covering approximately $28 \%$ of the US population [15]. The SEER database includes demographic information and cancer characteristics, such as diagnosis age, year of diagnosis, race, marital status, insurance status, income status, primary tumor location, tumor grade and stage, histological type, tumor-node-metastasis stage, treatment modality and survival time. In addition, the SEER database began publishing metastasis information related to liver, lung, bone and brain in 2010. The National Cancer Institute's SEER*Stat software (version 8.3.5; SEER 18 Regs Custom Data (with additional treatment field), November 2017 Sub (1973-2015 varying) database) was used in our study, we identified all 74,573 patients diagnosed with EC between 1 January 2010 and 31 December 2015.

Exclusion criteria in our study were as follows: patients under 18 years of age $(n=6)$; unknown survival time $(\mathrm{n}=100)$; unknown bone metastasis $(\mathrm{n}=1,568)$; unknown brain metastasis $(\mathrm{n}=28)$; unknown liver metastasis $(\mathrm{n}=34)$; unknown lung metastasis $(\mathrm{n}=66)$; unknown metastasis site $(\mathrm{n}=128)$; unknown insurance status $(\mathrm{n}=1,286)$; unknown income $(\mathrm{n}=3)$; other ICD-O-3 histology codes $(8000 / 3,8010 / 3,8013 / 3,8020 / 3,8041 / 3$, $8045 / 3,8050 / 3,8071 / 3,8072 / 3,8082 / 3,8246 / 3,8313 / 3,8370 / 3,8510 / 3,8574 / 3,8575 / 3, \mathrm{n}=2,327)[16]$. Finally, we left 69,027 eligible patients diagnosed with EC.

\section{Study variables}

Variable definition information about diagnostic age, year of diagnosis, race, marital status, insurance status, income status, tumor grade, histological type, lymph node involvement and survival time can be found in the SEER database. Overall survival (OS) and cancer-specific survival (CSS) were the primary study end points. Three-year OS, 5-year OS, 3-year CSS and 5-year CSS were also other interest outcomes in our study.

For the insurance status, patients were divided into three group: 'Insured group', 'medicaid group' and 'uninsured group'. The 'insured' and 'insured/no specifics' were defined as 'insured group', 'any medicaid' was defined as 'medicaid group', and 'uninsured' was clustered as 'uninsured group'.

For the marital status, patients were divided into 'married group', 'unmarried group' and 'unknown marital status group'. Unmarried patients include 'single', 'separated', 'divorced' and 'widowed'.

The ICD-0-3 site/histology validation list was used to distinguish endometrioid histology (endometrioid/ade nocarcinoma/mucinous, 8380--8383/3, 8140/3, 8210/3, 8211/3, 8560/3, 8260/3, 8262/3, 8263/3, 8570/3, 8261/3, 8480-8482/3 [17]; serous, 8441/3, 8460/3, 8461/3; carcinosarcoma, 8950/3, 8951/3, 8980/3, 8981/3; clear cell, 8310/3, and mixed epithelial, 8323/3, 8255/3).

Grade was defined by the following code; well differentiated (Grade I); moderately differentiated (Grade II); poorly differentiated (Grade III); undifferentiated (Grade IV) and unknown grade.

\section{Statistical analysis}

$\chi^{2}$ analysis was performed to evaluate clinical characteristics with organ metastasis. Kaplan-Meier curve was used to estimate the OS and CSS in different groups, and the difference between the curves was analyzed by log-rank test. Univariate and multivariate Cox regression models were performed to estimate the hazard ratios (HR) and 95\% CI to analyze independent prognostic factors. Statistical Package for the Social Sciences software (version 20.0; SPSS, IL, USA) was used for all statistical analyses. A p $\leq 0.05$ was considered statistically significant.

\section{Results}

\section{Demographic \& clinical characteristics}

A total of 69,027 EC patients who were eligible for our inclusion and exclusion were included in our study cohort from 1 January 2010 to 31 December 2015. Among them, there were 1048 (1.5\%) patients with lung metastasis, $541(0.8 \%)$ patients with liver metastasis, $388(0.6 \%)$ patients with bone metastasis and $105(0.2 \%)$ patients with brain metastasis. Demographic and clinical characteristics of EC patients with different organ metastasis were shown in Table 1.

\section{Lung metastasis}

Among the four types of organ metastasis, lung metastasis had the highest number and proportion of patients $(1048,1.5 \%)$. Over time, the number of lung metastasis increased from 284 (1.3\% in 2010-2011) to 394 (1.6\% in 2014-2015; $\mathrm{p}=0.037$ ). For race, non-Hispanic black patients had the highest rate of lung metastasis (188, 


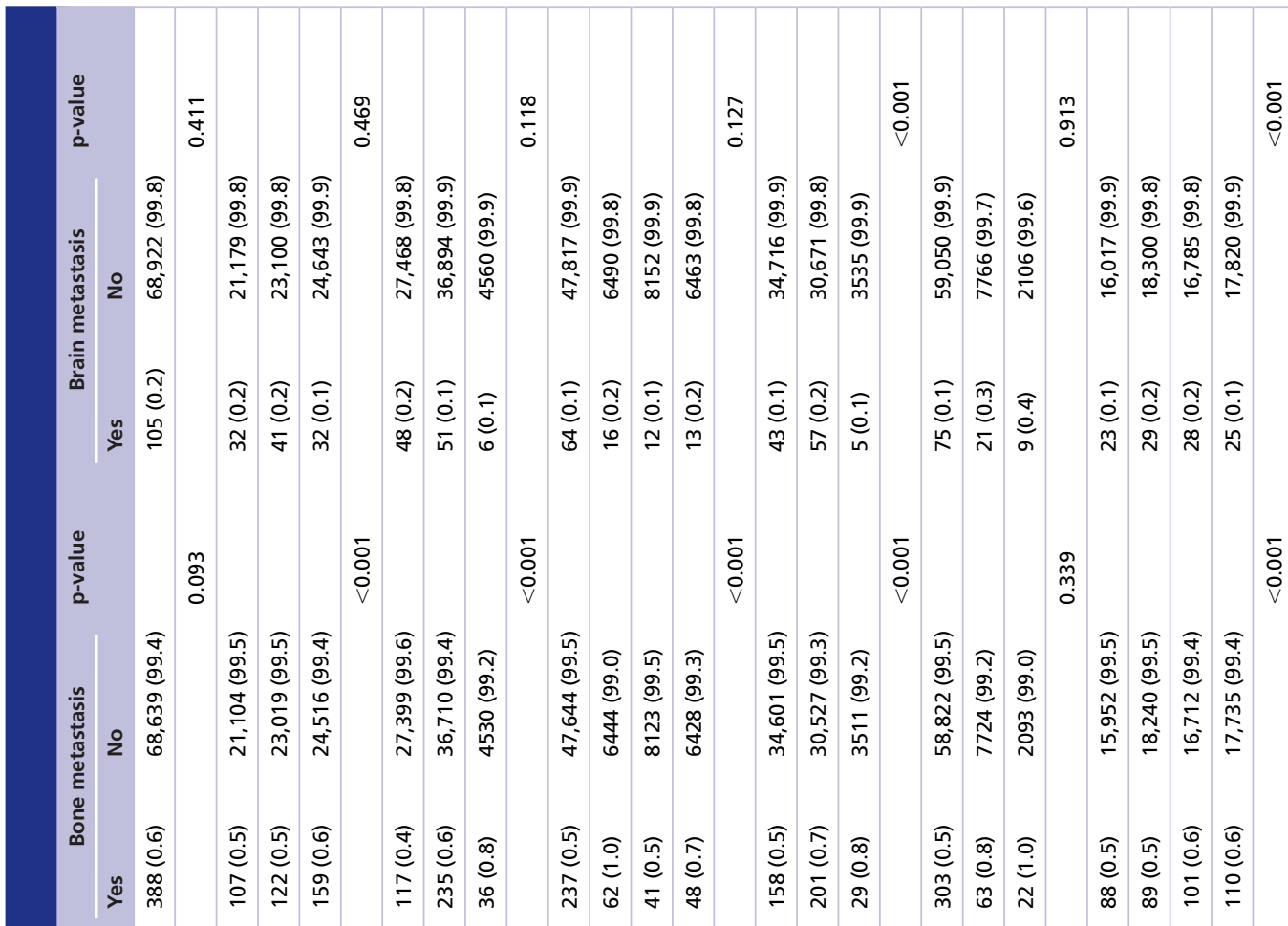

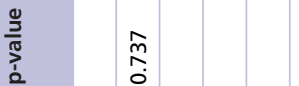

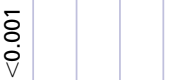

$\bar{o}$

$\bar{b}$

$\bar{\vdots}$

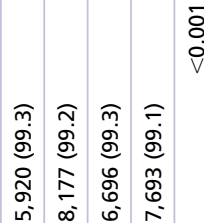

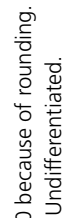

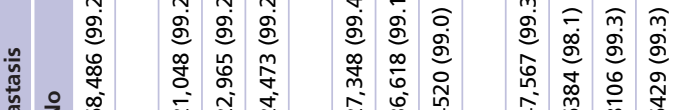

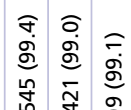

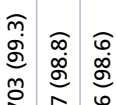

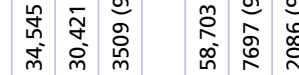

을

要

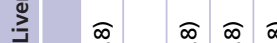

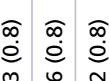

产

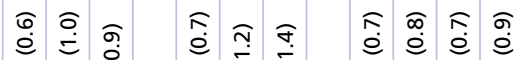

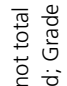

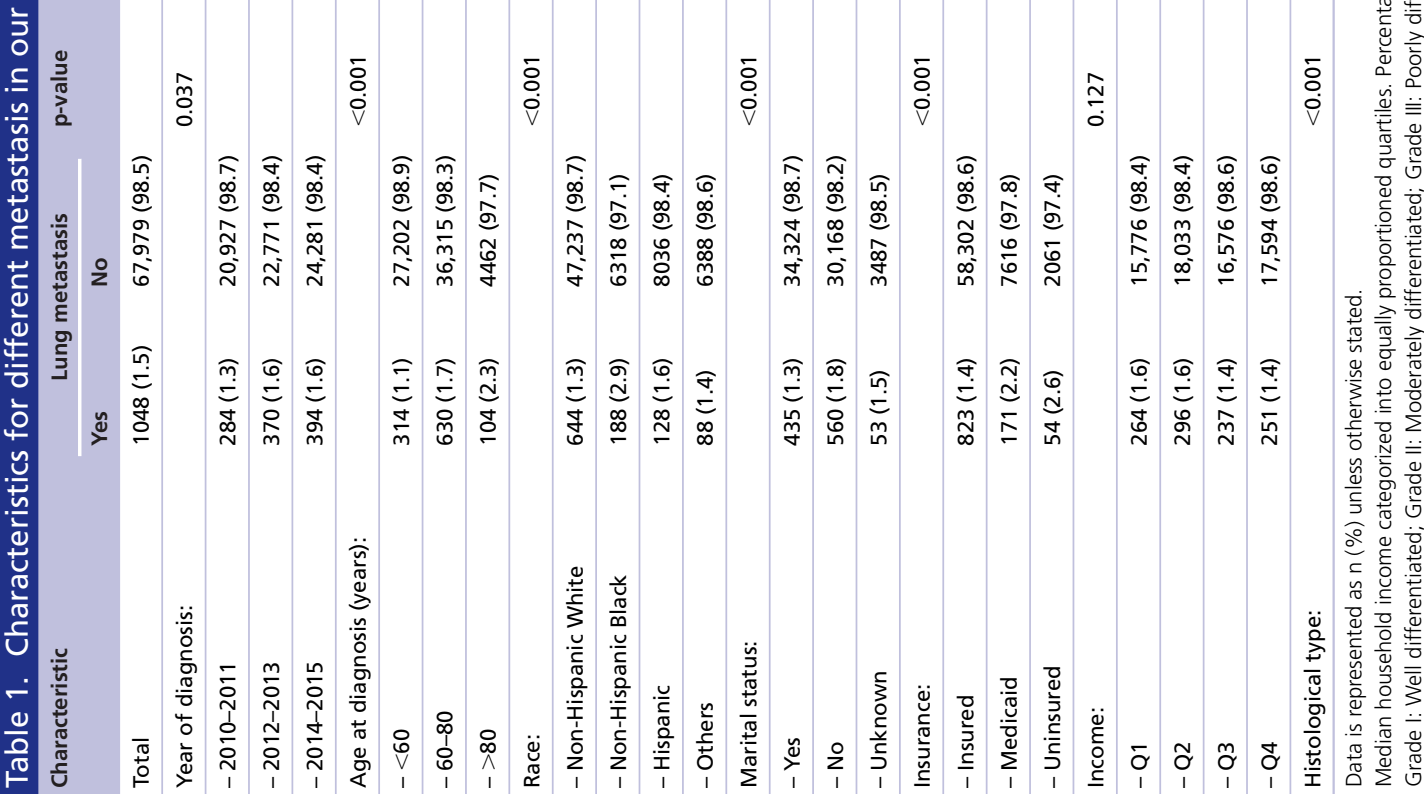




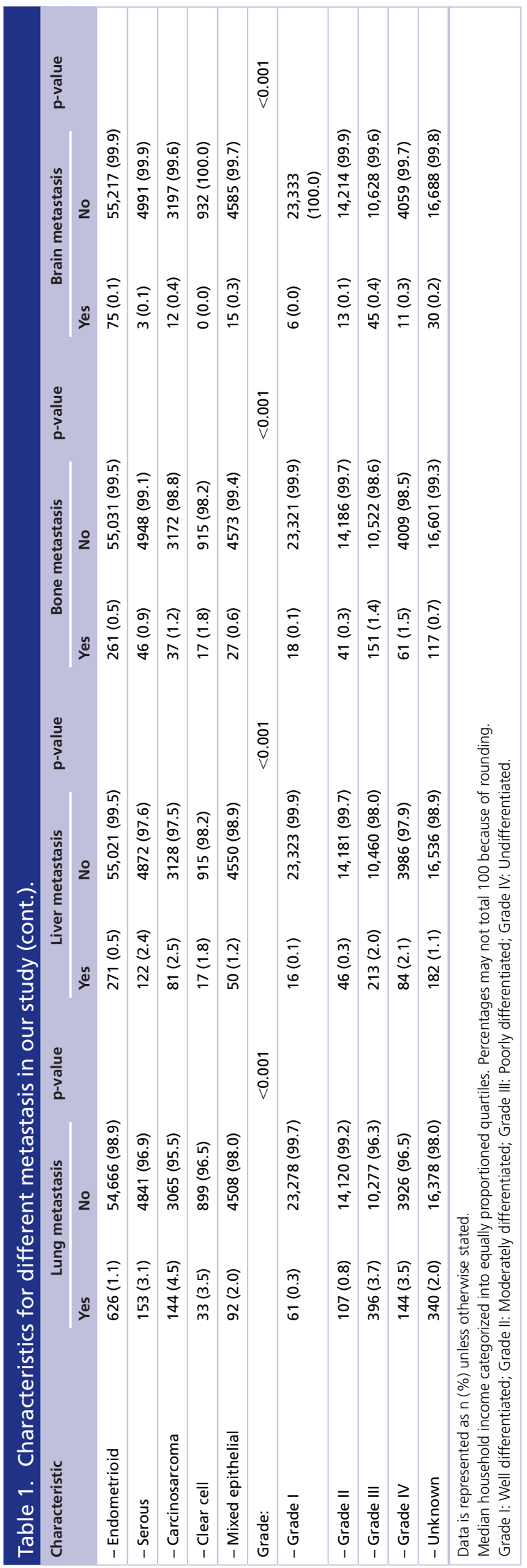




\begin{tabular}{|c|c|c|c|c|c|c|c|}
\hline Characteristic & Number (\%) & $\begin{array}{l}\text { Median OS } \\
\text { (months) }\end{array}$ & 3-year OS (\%) & 5-year OS (\%) & $\begin{array}{l}\text { Median CSS } \\
\text { (months) }\end{array}$ & 3-year CSS (\%) & 5-year CSS (\%) \\
\hline No metastasis & $67,434(97.69)$ & & 85 & 79 & & 91 & 88 \\
\hline \multicolumn{8}{|l|}{ One site: } \\
\hline - Only lung & $681(0.98)$ & 11 & 17 & 10 & 14 & 25 & 19 \\
\hline - Only liver & $297(0.43)$ & 10 & 17 & 10 & 15 & 27 & 21 \\
\hline - Only bone & $170(0.25)$ & 8 & 16 & 7 & 11 & 27 & 20 \\
\hline - Only brain & $41(0.06)$ & 5 & 10 & 10 & 8 & 21 & 21 \\
\hline \multicolumn{8}{|l|}{ Two sites: } \\
\hline - Lung and liver & $150(0.22)$ & 5 & 8 & 7 & 8 & 16 & 16 \\
\hline - Lung and bone & $117(0.17)$ & 9 & 18 & 14 & 11 & 24 & 19 \\
\hline - Lung and brain & $27(0.04)$ & 4 & 29 & 0 & 5 & 41 & 0 \\
\hline - Liver and bone & $24(0.03)$ & 6 & 11 & 0 & 19 & 20 & 0 \\
\hline - Liver and brain & $3(0.00)$ & 1 & 0 & 0 & 1 & 0 & 0 \\
\hline - Bone and brain & $6(0.01)$ & 3 & 17 & 0 & 3 & 21 & 0 \\
\hline \multicolumn{8}{|l|}{ Three sites: } \\
\hline - Lung, liver and bone & $49(0.07)$ & 4 & 3 & 0 & 5 & 8 & 0 \\
\hline - Lung, liver and brain & $6(0.01)$ & 1 & 0 & 0 & 1 & 0 & 0 \\
\hline - Lung, bone and brain & $10(0.01)$ & 2 & 0 & 0 & 4 & 0 & 0 \\
\hline - Liver, bone and brain & $4(0.01)$ & 2 & 0 & 0 & 2 & 0 & 0 \\
\hline \multicolumn{8}{|l|}{ Four sites: } \\
\hline - Lung, liver, bone and brain & $8(0.01)$ & 3 & 0 & 0 & 3 & 0 & 0 \\
\hline
\end{tabular}

2.9\%). Compared with unmarried patients, married patients had a lower rate of lung metastasis (1.3\%). Insured and medicaid patients had lower percentage of lung metastasis, while uninsured had highest lung metastasis rate $(2.6 \%)$. In terms of income, high income corresponds to low metastasis rates. For the tumor grade, undifferentiated tumors had the highest rate of lung metastasis (3.7\%). Among the histological types, the lung metastasis rate of carcinosarcoma was significantly higher $(4.5 \%$; p $<0.001)$ than other histological types.

\section{Liver metastasis}

Over time, the number of liver metastasis changed from 163 (0.8\% in 2010-2011) to 202 (0.8\% in 2014-2015), but there was no statistical significance. Patients with liver metastasis were significantly younger than those without liver metastasis. Non-Hispanic whites and Hispanics had significantly lower rates of liver metastasis than nonHispanic blacks ( $\mathrm{p}<0.001$ ). The rate of liver metastasis in unmarried or uninsured patients was higher than that in married or insured patients (All $\mathrm{p}<0.001$ ). In addition, the liver metastasis rate of poorly differentiated and undifferentiated tumors was higher, while that of well differentiated tumors was lower.

\section{Bone metastasis}

The characteristics of patients with bone metastasis were similar to those of liver metastasis. Bone metastasis are predisposed to elderly, non-Hispanic black, unmarried, uninsured, clear cell carcinoma type and undifferentiated patients (All $\mathrm{p}<0.001$ ).

\section{Brain metastasis}

Among the four types of organ metastasis, the number and proportion of patients with brain metastasis were the lowest $(132,0.2 \%)$. There was no significant difference in year of diagnosis, race, marital status and income between patients with and without brain metastasis (All $\mathrm{p}>0.05$ ). Similarly, brain metastasis was more likely to occur in elderly, uninsured, carcinosarcoma histological type and undifferentiated patients.

\section{Combination of metastasis patterns}

In our study, we found that some patients had multiple site metastasis. Table 2 summarizes all possible combinations of these four metastasis sites. Among the single organ metastasis, the proportion of lung metastasis was the highest 


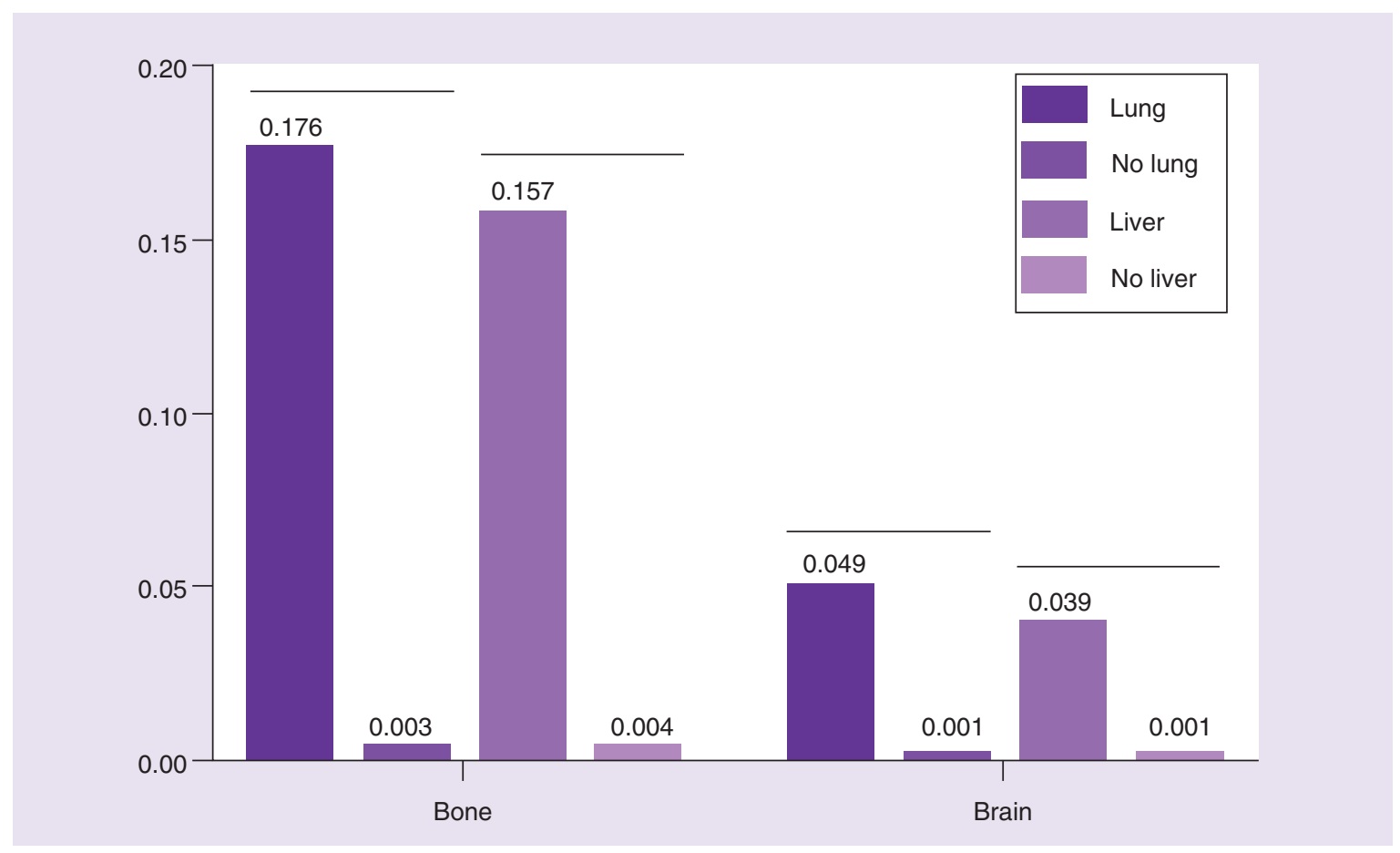

Figure 1. Comparisons of metastatic rate to bone and brain with and without liver or lung metastasis.

(681, $0.98 \%)$, followed by liver metastasis $(297,0.43 \%)$, bone metastasis $(170,0.25 \%)$ and finally brain metastasis $(41,0.06 \%)$. The most common combination of two-site metastasis was lung and liver $(150,0.22 \%)$. Of the three sites of metastasis, lung, liver and bone were the most common (49, 0.07\%). Only $8(0.01 \%)$ patients had all four sites metastasis.

In addition, we compared the risk of bone and brain metastases between EC patients with or without lung or liver metastases. We found that patients with lung metastases had a significantly higher risk of bone metastasis ( 17.6 vs $0.3 \%$ ) or brain metastasis ( 15.7 vs $0.4 \%$; Figure 1 ). A similar phenomenon was also found in patients with liver metastasis.

\section{Survival}

In our study, Kaplan-Meier curve was used to analyze the influence of related factors on OS and CSS of patients with EC (Table 3). Kaplan-Meier analysis showed that age at diagnosis, race, marital status, insurance status, income, tumor grade and organ metastasis were also significantly correlated with OS and CSS. The 5-year OS was 11 versus 79\% ( $\mathrm{p}<0.001)$ and 5-year CSS was 18 versus $88 \%(\mathrm{p}<0.001)$ for patients with or without lung metastasis (Figure 2A and Supplementary Figure 1A), 8 versus 78\% (p < 0.001) and 18 versus 87\% $(\mathrm{p}<0.001)$ for patients with or without liver metastasis (Figure 2B and Supplementary Figure 1B), 9 versus 78\% (p $<0.001$ ) and 16 versus $87 \%(\mathrm{p}<0.001)$ for patients with or without bone metastasis (Figure 2C and Supplementary Figure 1C), 10 versus $78 \%(\mathrm{p}<0.001)$ and 18 versus $87 \%(\mathrm{p}<0.001)$ for patients with or without brain metastasis (Figure 2D and Supplementary Figure 1D), respectively.

Table 2 shows the median OS, median CSS, 5-year OS and CSS for patients with different metastasis combinations. In patients with single organ metastasis, the median OS for patients with lung, liver, bone and brain metastasis was 11, 10, 8 and 5 months, respectively. Similarly, patients with lung, liver, bone and brain metastasis had median CSS at 14, 15, 11 and 8 months, respectively. Patients with brain metastasis alone had the worst OS and CSS (Figure 3A \& B).

In the two-site metastasis, the combination of lung and bone metastasis had the longest median OS (9 months), 5-year OS (18\%) and 5-year CSS (14\%; Figure 3C \& D). The combination of liver and brain metastasis had the shortest median OS (1 months), median CSS (1 months), 3-year OS (0\%) and 3-year CSS (0\%). In multi-sites 
Table 3. Kaplan-Meier analysis overall survival, cancer-specific survival, 3-year overall survival, 5-year overall survival, 3-year cancer-specific survival and 5-year cancer-specific survival for endometrial cancer patients.

\begin{tabular}{|c|c|c|c|c|c|c|c|c|}
\hline \multirow[t]{2}{*}{ Characteristic } & \multicolumn{2}{|c|}{ os } & \multirow{2}{*}{$\begin{array}{l}\text { 3-year OS } \\
\text { (\%) }\end{array}$} & \multirow{2}{*}{$\begin{array}{l}\text { 5-year OS } \\
(\%)\end{array}$} & \multicolumn{2}{|c|}{ CSS } & \multirow[t]{2}{*}{ 3-year CSS (\%) } & \multirow[t]{2}{*}{ 5-year CSS (\%) } \\
\hline & Log Rank & p-value & & & Log rank & p-value & & \\
\hline Age at diagnosis (years) & 4112.862 & $<0.001$ & & & 1674.793 & $<0.001$ & & \\
\hline$<60$ & & & 91 & 88 & & & 94 & 93 \\
\hline $60-80$ & & & 82 & 75 & & & 88 & 85 \\
\hline$>80$ & & & 55 & 41 & & & 73 & 69 \\
\hline Race & 975.396 & $<0.001$ & & & 717.818 & $<0.001$ & & \\
\hline Non-Hispanic White & & & 85 & 79 & & & 91 & 88 \\
\hline Non-Hispanic Black & & & 69 & 61 & & & 79 & 74 \\
\hline Hispanic & & & 85 & 80 & & & 91 & 88 \\
\hline Others & & & 88 & 82 & & & 92 & 89 \\
\hline Marital status & 790.919 & $<0.001$ & & & 379.584 & $<0.001$ & & \\
\hline Yes & & & 88 & 83 & & & 92 & 90 \\
\hline No & & & 79 & 72 & & & 87 & 84 \\
\hline Unknown & & & 84 & 78 & & & 90 & 88 \\
\hline Insurance & 268.701 & $<0.001$ & & & 121.566 & $<0.001$ & & \\
\hline Insured & & & 84 & 79 & & & 90 & 88 \\
\hline Medicaid & & & 77 & 68 & & & 86 & 82 \\
\hline Uninsured & & & 83 & 79 & & & 88 & 86 \\
\hline Income & 75.384 & $<0.001$ & & & 29.626 & $<0.001$ & & \\
\hline Q1 & & & 82 & 75 & & & 89 & 86 \\
\hline Q2 & & & 83 & 77 & & & 89 & 87 \\
\hline Q3 & & & 85 & 79 & & & 90 & 88 \\
\hline Q4 & & & 85 & 79 & & & 90 & 88 \\
\hline Histological type & 6529.535 & $<0.001$ & & & 6111.674 & $<0.001$ & & \\
\hline Endometrioid & & & 89 & 83 & & & 94 & 92 \\
\hline Serous & & & 60 & 47 & & & 69 & 61 \\
\hline Carcinosarcoma & & & 46 & 39 & & & 56 & 52 \\
\hline Clear cell & & & 62 & 56 & & & 72 & 67 \\
\hline Mixed epithelial & & & 78 & 71 & & & 85 & 81 \\
\hline Grade & 6336.681 & $<0.001$ & & & 5991.059 & $<0.001$ & & \\
\hline Grade I & & & 95 & 91 & & & 98 & 97 \\
\hline Grade II & & & 89 & 82 & & & 94 & 91 \\
\hline Grade III & & & 65 & 56 & & & 74 & 69 \\
\hline Grade IV & & & 57 & 47 & & & 66 & 60 \\
\hline Unknown & & & 81 & 75 & & & 88 & 86 \\
\hline Lung metastasis & 7479.633 & $<0.001$ & & & 7450.995 & $<0.001$ & & \\
\hline Yes & & & 15 & 11 & & & 23 & 18 \\
\hline No & & & 85 & 79 & & & 90 & 88 \\
\hline Liver metastasis & 4629.810 & $<0.001$ & & & 4160.889 & $<0.001$ & & \\
\hline Yes & & & 14 & 8 & & & 22 & 18 \\
\hline No & & & 84 & 78 & & & 90 & 87 \\
\hline Bone metastasis & 3108.112 & $<0.001$ & & & 3142.567 & $<0.001$ & & \\
\hline Yes & & & 15 & 9 & & & 21 & 16 \\
\hline No & & & 84 & 78 & & & 90 & 87 \\
\hline Brain metastasis & 1238.294 & $<0.001$ & & & 1182.280 & $<0.001$ & & \\
\hline Yes & & & 10 & 10 & & & 18 & 18 \\
\hline No & & & 84 & 78 & & & 90 & 87 \\
\hline
\end{tabular}



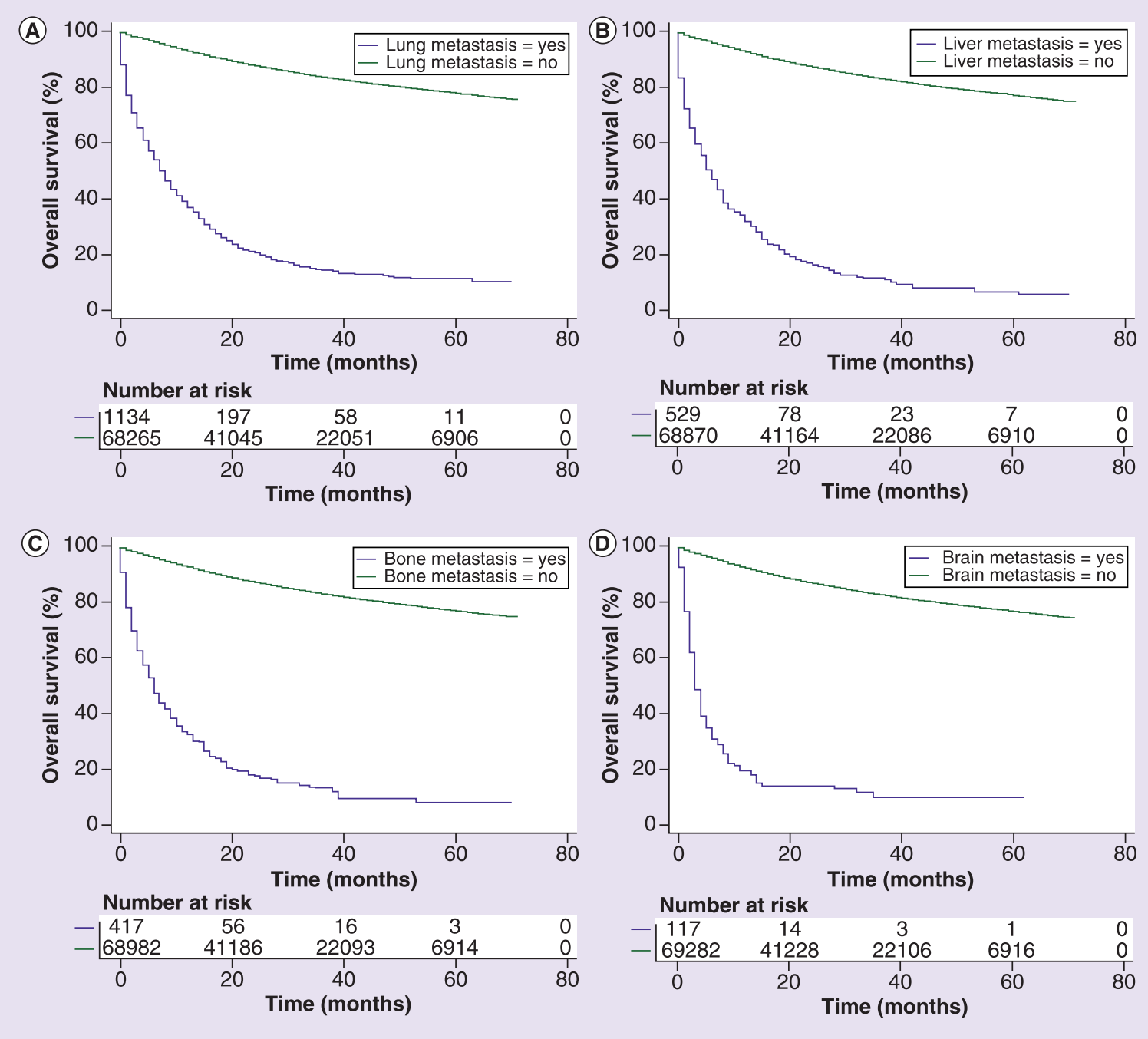

Figure 2. Overall survival curves between patients with and without metastasis. With and without lung metastasisp $<0.001$ (A) with and without liver metastasis; $p<0.001$ (B) with and without bone metastasis; $p<0.001$ (C) with and without brain metastasis; $p<0.001$ (D).

metastasis, the survival time of the patients was very short, with both 3-year OS and CSS 0\% (Figure 3E \& F). In addition, OS and CSS decreased with the increase of metastatic sites (Figure 4A \& B).

\section{Identification of prognostic factors of OS in EC patients}

Univariate and multivariate cox regression were used to analyze the factors associated with OS and CSS in EC patients. As shown in Table $4 \& 5$, age at diagnosis, race, marital status, insurance status, income, histological type, grad and whether metastasis are factors that affect the OS and CSS in patients with EC. Multivariate cox regression showed no lung metastasis (vs lung metastasis; $H R=0.21,95 \%$ CI: 0.19-0.23; $p<0.001$ ), no liver metastasis (vs liver metastasis; $\mathrm{HR}=0.31 ; 95 \% \mathrm{CI}: 0.28-0.35$; $\mathrm{p}<0.001$ ), no bone metastasis (vs bone metastasis; $\mathrm{HR}=0.41 ; 95 \%$ CI: 0.36-0.47; $\mathrm{p}<0.001$ ); no brain metastasis (vs brain metastasis; HR = 0.36; 95\% CI: 0.29$0.45 ; \mathrm{p}<0.001$ ) were associated with better OS (Figure 5). Similarly, in terms of CSS, multivariate Cox regression analysis also indicated whether organ metastasis was a prognostic factor for EC patients (no lung metastasis vs lung metastasis, HR $=0.18 ; 95 \%$ CI: 0.17-0.21; $<<0.001$; no liver metastasis vs liver metastasis, HR $=0.32 ; 95 \%$ CI: 0.28-0.37; $\mathrm{p}<0.001$; no bone metastasis vs bone metastasis, $\mathrm{HR}=0.38$; $95 \% \mathrm{CI}$ : $0.32-0.44 ; \mathrm{p}<0.001$; no brain metastasis vs brain metastasis, HR $=0.36$; $95 \%$ CI 0.28-0.47; $\mathrm{p}<0.001$; Supplementary Figure 2). 
(A)

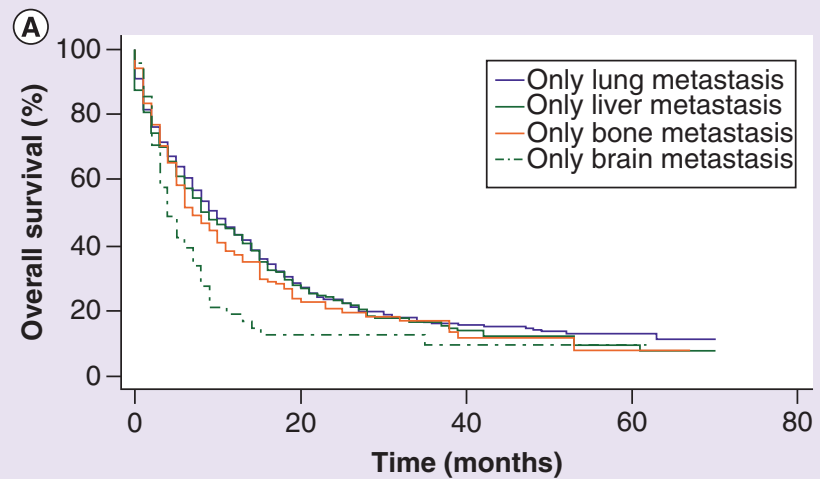

Time (months)
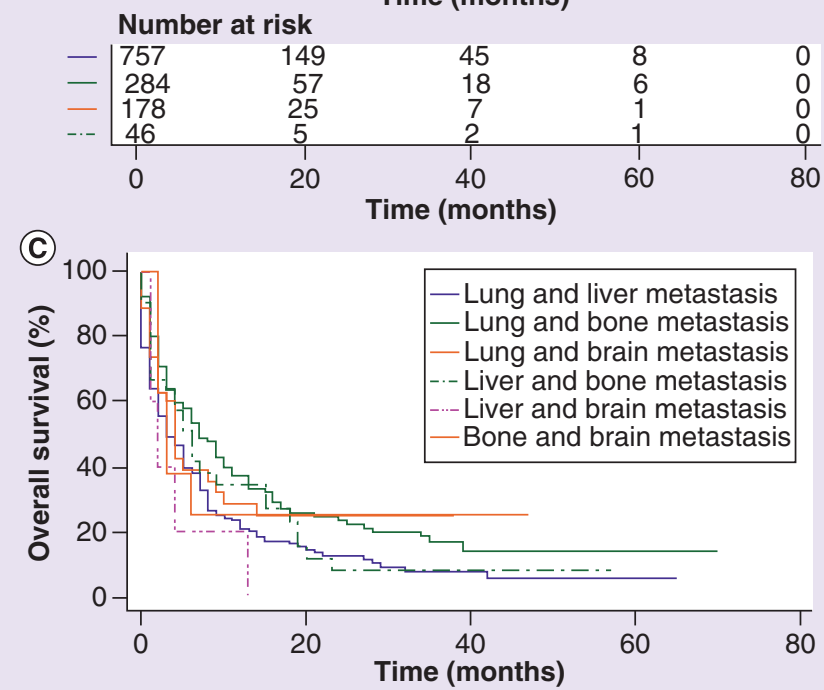

Number at risk

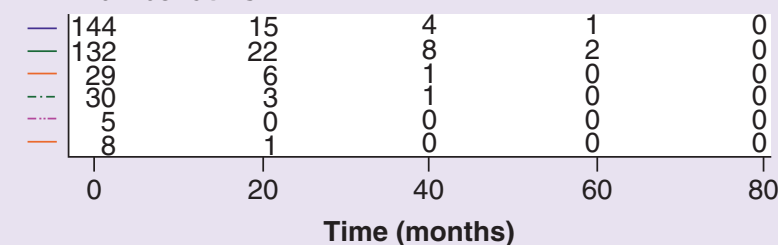

(E)

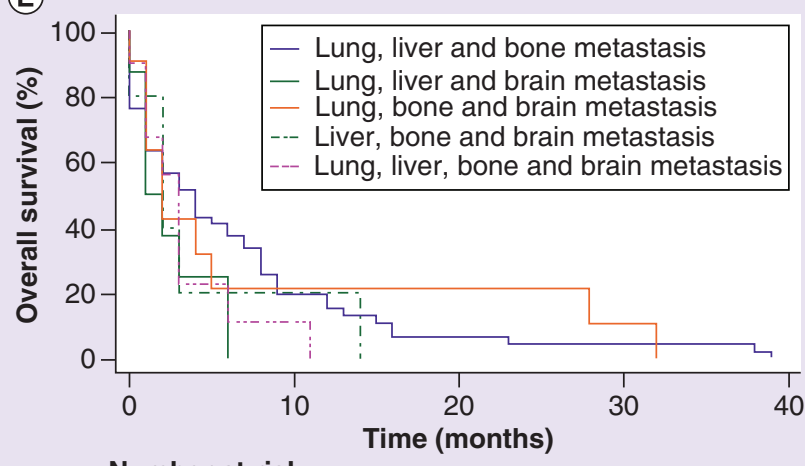

Number at risk

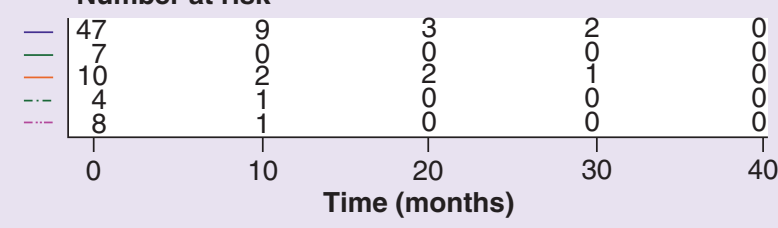

(B)
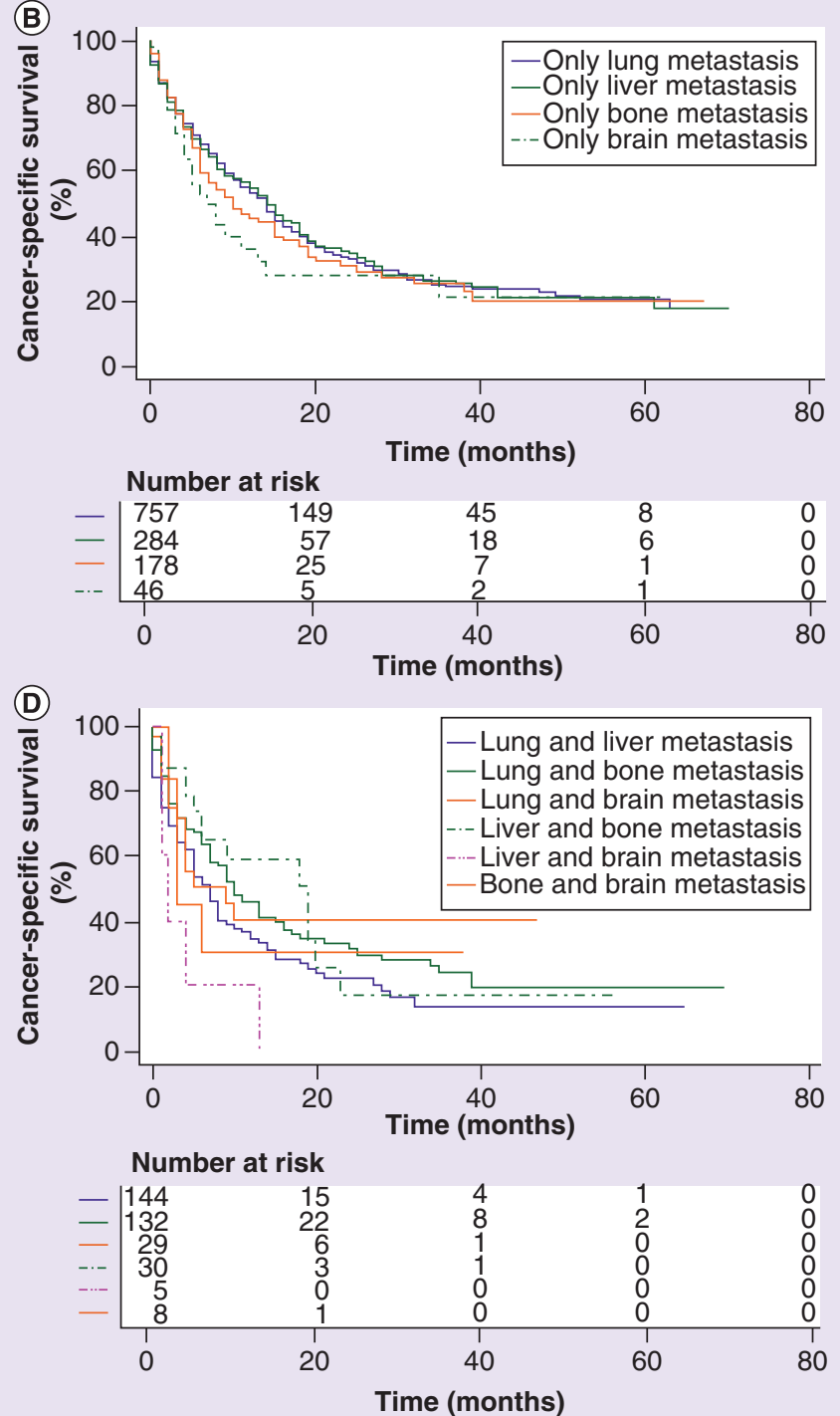

(F)
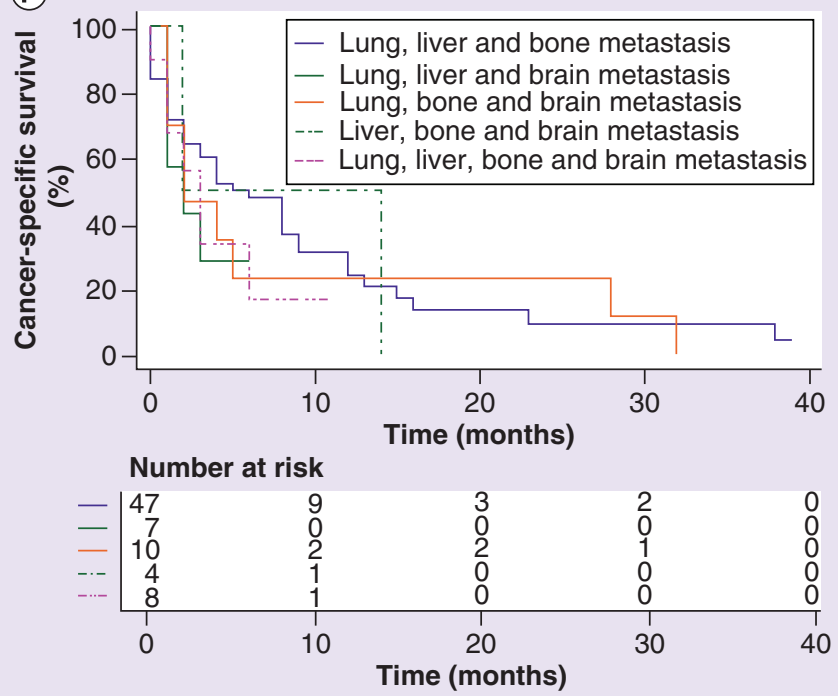

Figure 3. Overall survival and cancer-specific survival curves of endometrial cancer patients according to different metastasis pattern. (A \& B) OS and CSS in single organ metastasis. (C \& D) OS and CSS in two-site organ metastasis. (E \& F) OS and CSS in multisite organ metastasis.

CSS: Cancer-specific survival; OS: Overall survival. 
Table 4. Univariate and multivariate analysis of overall survival rates.

\begin{tabular}{|c|c|c|c|c|}
\hline \multirow[t]{2}{*}{ Characteristic } & \multicolumn{2}{|c|}{ Univariate analysis } & \multicolumn{2}{|c|}{ Multivariate analysi } \\
\hline & Hazard ratio $(95 \% \mathrm{Cl})$ & p-value & Hazard ratio $(95 \% \mathrm{Cl})$ & $\mathrm{p}$-value \\
\hline \multicolumn{5}{|c|}{ Age at diagnosis (years) } \\
\hline$<60$ & Reference & & Reference & \\
\hline $60-80$ & $2.23(2.12-2.34)$ & $<0.001$ & $1.77(1.68-1.87)$ & $<0.001$ \\
\hline$>80$ & $6.60(6.20-7.03)$ & $<0.001$ & $4.62(4.32-4.94)$ & $<0.001$ \\
\hline \multicolumn{5}{|l|}{ Race } \\
\hline Non-Hispanic Black & $2.19(2.08-2.32)$ & $<0.001$ & $1.38(1.30-1.46)$ & $<0.001$ \\
\hline Hispanic & $0.97(0.91-1.04)$ & 0.383 & $1.00(0.93-1.07)$ & 0.925 \\
\hline Others & $0.82(0.76-0.89)$ & $<0.001$ & $0.91(0.84-0.99)$ & 0.025 \\
\hline \multicolumn{5}{|l|}{ Marital status } \\
\hline Yes & Reference & & Reference & \\
\hline Medicaid & $1.59(1.50-1.68)$ & $<0.001$ & $1.46(1.37-1.55)$ & $<0.001$ \\
\hline Uninsured & $1.11(1.00-1.25)$ & 0.061 & $1.34(1.20-1.50)$ & $<0.001$ \\
\hline \multicolumn{5}{|l|}{ Income } \\
\hline Q1 & Reference & & Reference & \\
\hline Q2 & $0.93(0.88-0.98)$ & 0.006 & $0.93(0.88-0.98)$ & 0.007 \\
\hline Q3 & $0.81(0.77-0.86)$ & $<0.001$ & $0.83(0.79-0.88)$ & $<0.001$ \\
\hline Q4 & $0.81(0.77-0.86)$ & $<0.001$ & $0.84(0.80-0.89)$ & $<0.001$ \\
\hline \multicolumn{5}{|l|}{ Histological type } \\
\hline Endometrioid & Reference & & Reference & \\
\hline Grade III & $7.31(6.84-7.81)$ & $<0.001$ & $4.03(3.74-4.33)$ & $<0.001$ \\
\hline Grade IV & $9.50(8.79-10.28)$ & $<0.001$ & $4.36(3.99-4.76)$ & $<0.001$ \\
\hline Unknown & $3.62(3.37-3.88)$ & $<0.001$ & $2.68(2.49-2.88)$ & $<0.001$ \\
\hline \multicolumn{5}{|l|}{ Lung metastasis } \\
\hline Yes & Reference & & Reference & \\
\hline No & $0.08(0.07-0.08)$ & $<0.001$ & $0.21(0.19-0.23)$ & $<0.001$ \\
\hline \multicolumn{5}{|l|}{ Liver metastasis } \\
\hline Yes & Reference & & Reference & \\
\hline No & $0.07(0.07-0.08)$ & $<0.001$ & $0.31(0.28-0.35)$ & $<0.001$ \\
\hline \multicolumn{5}{|l|}{ Bone metastasis } \\
\hline Yes & Reference & & Reference & \\
\hline No & $0.08(0.07-0.09)$ & $<0.001$ & $0.41(0.36-0.47)$ & $<0.001$ \\
\hline \multicolumn{5}{|l|}{ Brain metastasis } \\
\hline Yes & Reference & & Reference & \\
\hline No & $0.06(0.05-0.07)$ & $<0.001$ & $0.36(0.29-0.45)$ & $<0.001$ \\
\hline
\end{tabular}


Table 5. Univariate and multivariate analysis of cancer-specific survival rates.

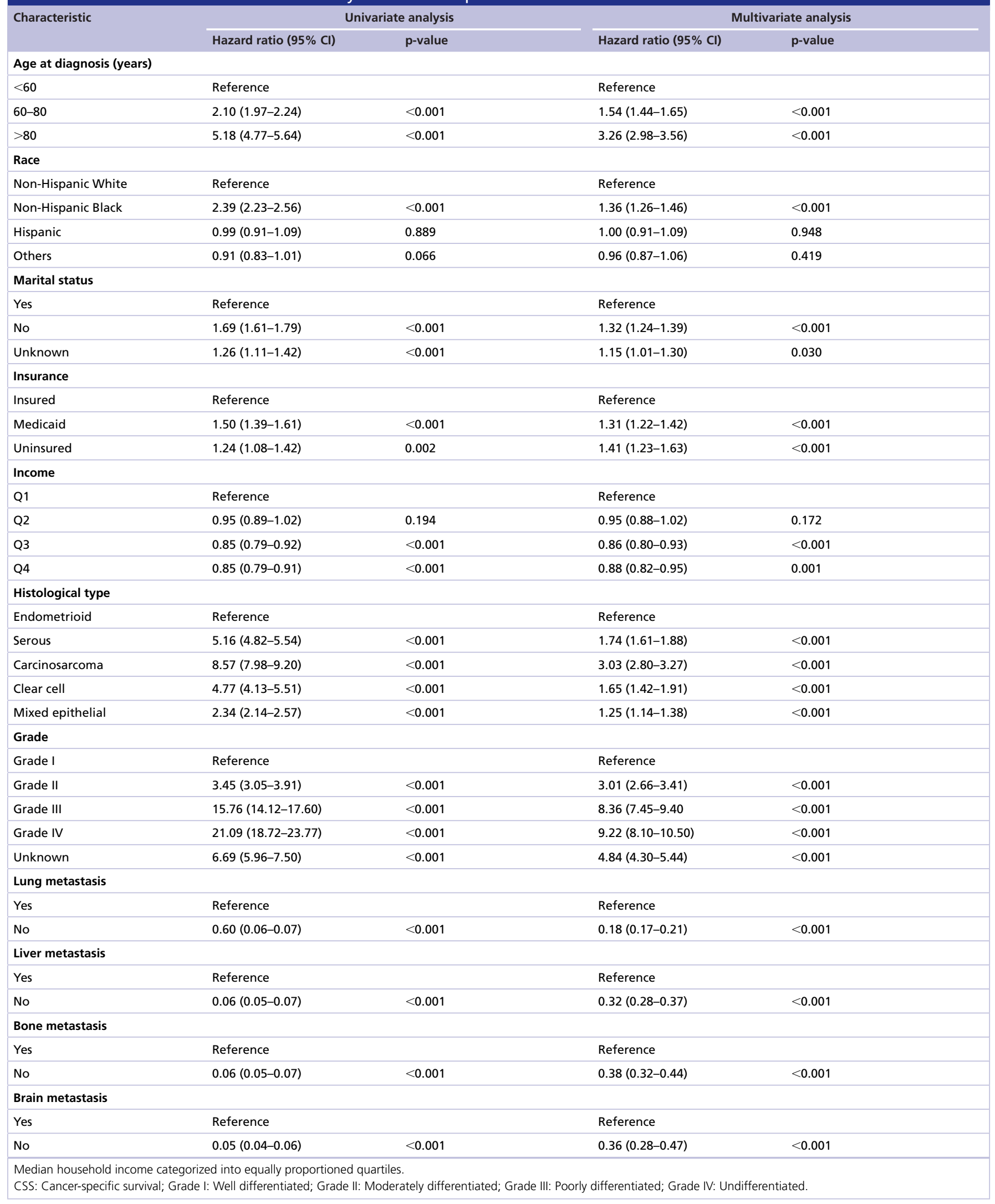


(A)

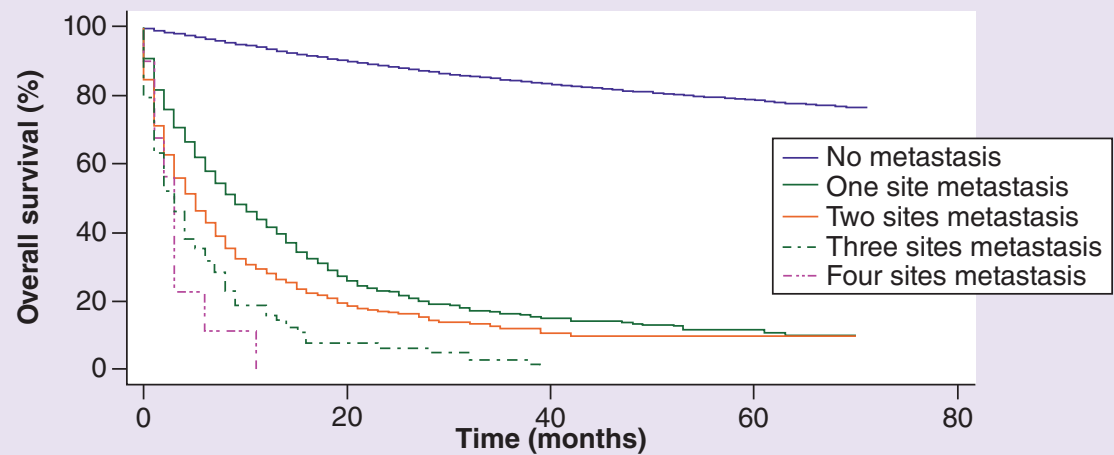

Number at risk

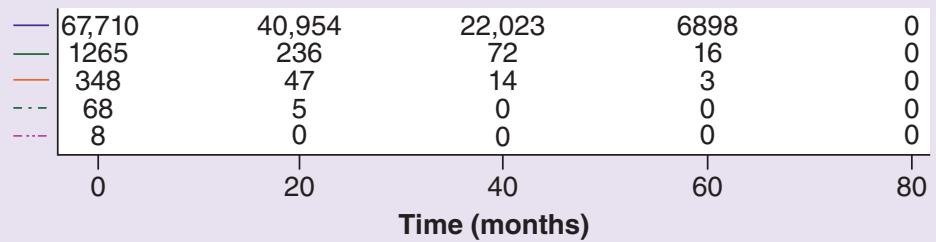

(B)
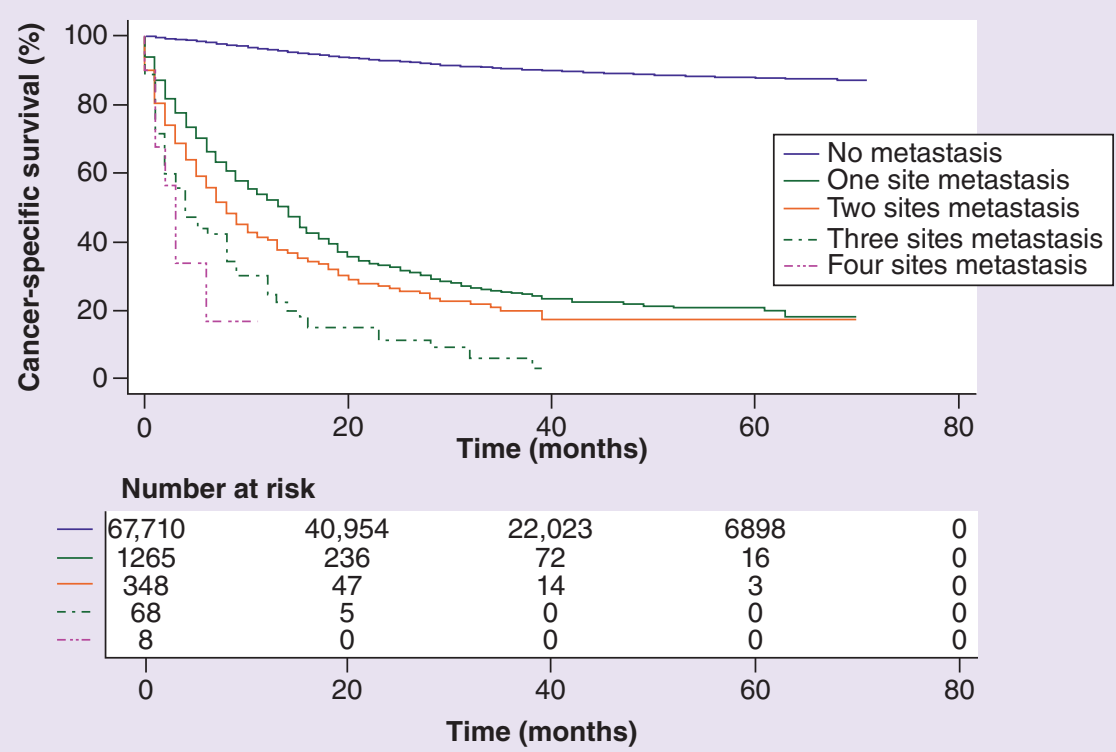

Figure 4. Overall survival and cancer-specific survival curves of EC patients according to the number of different metastatic sites. (A) Overall survival (B) cancer-specific survival.

EC: Endometrial cancer

\section{Discussion}

Our study reported the different organ metastasis of EC patients through a large population-based case study. Our study showed that in patients with EC, distant organ metastasis was more common in lung metastasis (1.5\%), followed by liver metastasis $(0.8 \%)$ and bone metastasis $(0.6 \%)$, and brain metastasis was rare (only $0.2 \%)$. In the single organ metastasis, lung metastasis has the longest survival time, and brain metastasis has the shortest survival time. In two-site metastasis, the combination of lung and bone metastasis had the longest median OS (9 months), and the combination of liver and brain metastasis had the shortest median OS (1 month) and median CSS (1 month). In multi-site metastasis, the survival time of the patients was very short, with both 3-year OS and CSS $0 \%$. In addition, OS and CSS decreased with the increase of metastasis site. 


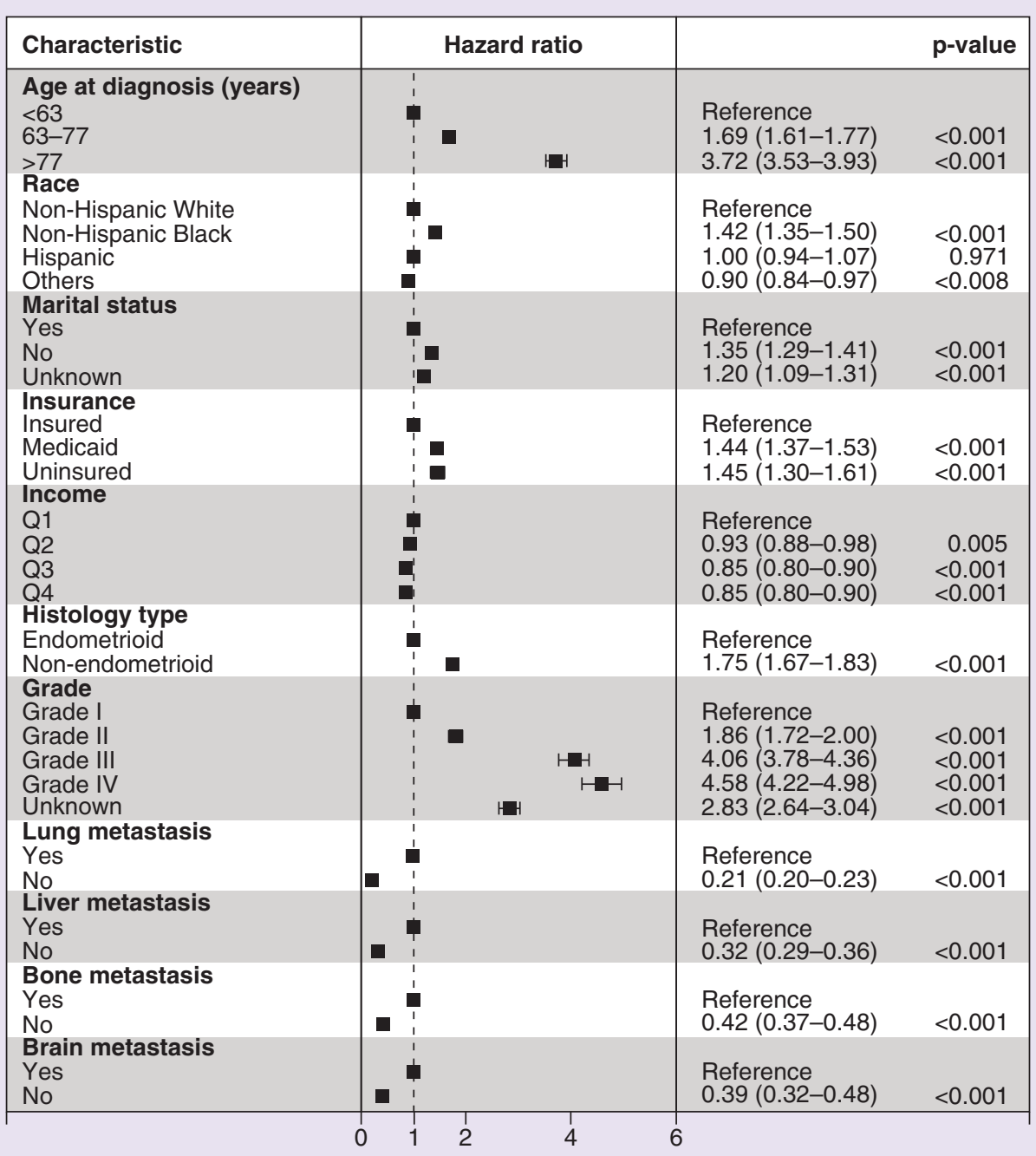

Figure 5. Forest plot of Multivariable Cox analyses of overall survival adjusted by the age at diagnosis, race, marital status, insurance status, economic income, histological type, grade and organ metastatic. The black squares on the transverse lines represent the hazard ratio, and the transverse lines represent $95 \% \mathrm{Cl}$.

EC is one of the common malignant tumors in gynecology. The modes of metastasis in patients with EC include intra-abdominal spread, lymph node involvement and distant organ metastasis [18,19]. Distant organ metastasis (lung, liver, brain or bone) is very rare, but it has a great impact on the prognosis and survival of EC patients. There are few studies on distant metastasis in patients with EC, and most of them focus on single metastasis site or specific stage. Liu et al. [20] through the study of 2948 patients with stage IV EC from 2010 to 2014, found that the most common metastasis site of stage IV EC was the lung, while the survival rate of patients with brain metastasis was the worst. Ignatov et al. [21] described the recurrence pattern of EC according to the risk characteristics through a 7-year follow-up of $2177 \mathrm{EC}$ patients. It was found that patients with different EC subtypes had specific recurrence patterns and recurrence time, and high-risk patients needed shorter follow-up time.

Data from current analysis showed that lung metastasis was the most common distant organ metastasis, while brain metastasis is the rarest distant organ metastasis, which is consistent with previous retrospective studies [22-24]. In addition, the analysis of our study was performed on a larger sample size and provided information on the proportion and prognosis time of different metastasis sites and combinations of different metastasis sites. We also found that the pattern of distant metastasis appears to be influenced by the histological type of patients. The histological type of carcinosarcoma had significantly higher rate of lung, liver and brain metastasis, while clear cell type was more likely to have bone metastasis. EC patients with lung or liver metastasis were at higher risk of bone 
and brain metastases than those without lung and liver metastasis. This is consistent with previous research on other types of cancer [25,26].

Some researchers believe that the combination of liver metastasis and brain metastasis is unusual, because the lungs are often the first filter, and the occurrence of brain metastasis is usually associated with lung metastasis. Through the investigation of 45 patients with brain metastasis of colorectal cancer, Sun et al. [27] found that 19 patients were not complicated with lung metastasis. Our study also found that not all patients with brain metastasis were associated with lung metastasis, which may be due to the metastasis of tumor cells into the brain through the prevertebral venous plexus.

Our analysis found that the percentage of lung, liver, bone and brain metastasis in uninsured patients was significantly higher than that in insured patients. This may be because insured EC patients have more opportunities to receive surgical treatment for a better prognosis [28]. In addition, in terms of race, non-Hispanic black patients are more likely to have metastasis than Hispanic-white patients, which was consistent with previous study [29]. Moreover, married EC patients are less likely to have metastasis, and married patients have a lower risk of OS and CSS, perhaps because spouses can provide social support and encourage patients to seek medical help [30,31].

In our study, we found not only the difference in prognosis of single organ metastasis, but also the difference between single organ metastasis and multiple organ metastasis, which were similar to the data from other solid tumors [32,33]. Abdel-Rahman [34] found that liver metastasis had the worst survival time in renal cell carcinoma single organ metastasis. Qiu et al. [35] found that in gastric cancer, lung and bone metastasis had the longest median OS (9 months) in two-site metastasis, while liver and brain metastasis had the shortest median OS (1 months) and 5 -year CSS (0\%).

There are limitations to be recognized in this study. First, this study is a retrospective study with obvious limitations. Second, there is no FIGO grading system for EC patients in the SEER database, only the Grade classification, which still requires for conversion. In addition, the SEER database began to release metastasis information related to liver, lung, bone and brain in 2010 and the follow-up period was not long enough. We can only obtain information about organ metastasis, and the sequence of metastasis information is not mentioned in the SEER database. Moreover, the lack of information on the physical condition and complications of patients, both of which are prognostic factors for metastasis in patients with EC.

Information about the impact of distant organ metastasis on the prognosis of patients with EC will be helpful for the proper stratification of advanced patients and for clinicians to determine appropriate follow-up strategies, and guide clinicians to design personalized pretreatment for EC patients.

\section{Conclusion}

In our study, we found that organ metastasis is an independent prognostic factor for survival in EC patients. In single organ metastasis, lung metastasis has the best survival time. Assessing distant organ metastasis and metastasis pattern can help clinicians design personalized treatment for patients with advanced EC.

\section{Summary points}

- Endometrial cancer (EC) is the most common carcinoma of the female reproductive tract in developed countries.

- Large population-based studies on the clinicopathological features of lung, liver, bone and brain metastasis in patients with EC are relatively few.

- Our study investigated the pattern of distant organ metastasis in patients with EC.

- Lung metastasis was most common, followed by liver metastasis and bone metastasis, and brain metastases were rare.

- EC patients with lung or liver metastasis were at higher risk of bone and brain metastases than those without lung and liver metastasis.

- Brain metastasis has the lowest survival time in single organ metastasis.

- Liver and brain metastasis have the highest death rate in two organ metastasis.

- The combination of lung, liver and brain metastasis had the lowest survival time in multi-sites metastasis. 


\section{Acknowledgments}

The authors are grateful for the invaluable support and useful discussions with other members of the obstetrics and gynecology department.

Financial \& competing interests disclosure

The authors have no relevant affiliations or financial involvement with any organization or entity with a financial interest in or financial conflict with the subject matter or materials discussed in the manuscript. This includes employment, consultancies, honoraria, stock ownership or options, expert testimony, grants or patents received or pending, or royalties.

No writing assistance was utilized in the production of this manuscript.

\section{Ethical conduct of research}

This article does not contain any studies with human participants performed by any of the authors. No ethics approval was sought for this study by authors as data used were the National Cancer Institute's SEER database, which is a publicly available de-identified population-based database.

\section{Open access}

This work is licensed under the Attribution-NonCommercial-NoDerivatives 4.0 Unported License. To view a copy of this license, visit http://creativecommons.org/licenses/by-nc-nd/4.0/

\section{References}

Papers of special note have been highlighted as: $\bullet$ of interest; $\bullet \bullet$ of considerable interest

1. Bray F, Ferlay J, Soerjomataram I, Siegel RL, Torre LA, Jemal A. Global cancer statistics 2018: GLOBOCAN estimates of incidence and mortality worldwide for 36 cancers in 185 countries. CA Cancer J. Clin. 68(6), 394-424 (2018).

2. Siegel RL, Miller KD, Jemal A. Cancer statistics, 2018. CA Cancer J. Clin. 68(1), 7-30 (2018).

3. Ferlay J, Soerjomataram I, Dikshit $\mathrm{R}$ et al. Cancer incidence and mortality worldwide: sources, methods and major patterns in GLOBOCAN 2012. Int. J. Cancer 136(5), E359-386 (2015).

4. Doulgeraki T, Vagios S, Kavoura E et al. Mismatch repair status in high-grade endometrial carcinomas of endometrioid and non-endometrioid type. J. BUON 24(5), 2020-2027 (2019).

5. Sanderson PA, Moulla A, Scott Fegan K. Endometrial cancer - an update. Obstet. Gynecol. 29(8), 225-232 (2019).

6. Brooks RA, Fleming GF, Lastra RR et al. Current recommendations and recent progress in endometrial cancer. CA Cancer J. Clin. 69(4), 258-279 (2019).

-• Introduces the current recommendations and recent progress of endometrial cancer (EC).

7. Morice P, Leary A, Creutzberg C, Abu-Rustum N, Darai E. Endometrial cancer. Lancet 387(10023), 1094-1108 (2016).

-. The research progress of endometrial carcinoma was introduced.

8. National Cancer Institute. Endometrial cancer treatment (PDQ $\mathbb{R})$ : health professional version. In: PDQ Cancer Information Summaries Bethesda (MD) (2002). www.ncbi.nlm.nih.gov/books/NBK65829/

9. Walker JL, Piedmonte MR, Spirtos NM et al. Laparoscopy compared with laparotomy for comprehensive surgical staging of uterine cancer: Gynecologic Oncology Group Study LAP2. J. Clin. Oncol. 27(32), 5331-5336 (2009).

10. Mourits MJ, Bijen CB, Arts $\mathrm{HJ}$ et al. Safety of laparoscopy versus laparotomy in early-stage endometrial cancer: a randomised trial. Lancet Oncol. 11(8), 763-771 (2010).

11. Backes FJ, Brudie LA, Farrell MR et al. Short- and long-term morbidity and outcomes after robotic surgery for comprehensive endometrial cancer staging. Gynecol. Oncol. 125(3), 546-551 (2012).

12. Koh WJ, Abu-Rustum NR, Bean S et al. Uterine neoplasms, Version 1.2018 Clinical Practice Guidelines in Oncology. J. Natl Compr Canc. Ne. 16(2), 170-199 (2018).

13. Mariani A, Webb MJ, Keeney GL, Podratz KC. Routes of lymphatic spread: a study of 112 consecutive patients with endometrial cancer. Gynecol. Oncol. 81(1), 100-104 (2001).

14. Sohaib SA, Houghton SL, Meroni R, Rockall AG, Blake P, Reznek RH. Recurrent endometrial cancer: patterns of recurrent disease and assessment of prognosis. Clin. Radiol. 62(1), 28-34 (2007).

15. Mao W, Huang X, Kong M, Fan J, Geng J. More lymph node dissection improves survival in patients with newly diagnosed lymph node-positive penile cancer. Int. Urol. Nephrol. 51(4), 641-654 (2019).

16. Cosgrove CM, Cohn DE, Rhoades J, Felix AS. The prognostic significance of aortic lymph node metastasis in endometrial cancer: potential implications for selective aortic lymph node assessment. Gynecol. Oncol. 153(3), 505-510 (2019). 
17. Matsuo K, Machida H, Frimer M et al. Prognosis of women with stage I endometrioid endometrial cancer and synchronous stage I endometrioid ovarian cancer. Gynecol. Oncol. 147(3), 558-564 (2017).

18. Lewin SN. Revised FIGO staging system for endometrial cancer. Clin. Obstet. Gynecol. 54(2), 215-218 (2011).

19. Uccella S, Morris JM, Multinu F et al. Primary brain metastases of endometrial cancer: a report of 18 cases and review of the literature. Gynecol. Oncol. 142(1), 70-75 (2016).

20. Liu Y, Chi S, Zhou X, Zhao R, Xiao C, Wang H. Prognostic value of distant metastatic sites in stage IV endometrial cancer: A SEER database study of 2948 women. Int. J. Gynaecol. Obstet. 149 (1), 16- 23 (2019).

- Through the study of 2948 cases of IV endometrial carcinoma in Surveillance, Epidemiology and End Results database, the prognostic value of distant metastasis of IV endometrial carcinoma was investigated.

21. Ignatov T, Eggemann H, Costa SD, Ortmann O, Ignatov A. Endometrial cancer subtypes are associated with different patterns of recurrence. J. Cancer Res. Clin. Oncol. 144(10), 2011-2017 (2018).

-• Ignatov et al. described the recurrence pattern of EC according to the risk characteristics through a 7-year follow-up of 2177 EC patients, and found that patients with different EC subtypes have specific recurrence patterns and recurrence time.

22. Jiang W, Chen J, Tao X et al. Possible risk factors of pulmonary metastases in patients with international federation of gynecology and obstetrics Stage I endometrioid-type endometrial cancer. Int. J. Gynecol. Cancer 27(6), 1195-1204 (2017).

23. Doger E, Cakiroglu Y, Ozdamar $\mathrm{O}$ et al. Bone metastasis in endometrial cancer: evaluation of treatment approaches by factors affecting prognosis. Eur. J. Gynaecol. Oncol. 37(3), 407-416 (2016).

24. Kehoe SM, Zivanovic O, Ferguson SE, Barakat RR, Soslow RA. Clinicopathologic features of bone metastases and outcomes in patients with primary endometrial cancer. Gynecol. Oncol. 117(2), 229-233 (2010).

25. Qiu MZ, Shi SM, Chen ZH et al. Frequency and clinicopathological features of metastasis to liver, lung, bone, and brain from gastric cancer: a SEER-based study. Cancer Med. 7(8), 3662-3672 (2018).

26. Qiu M, Hu J, Yang D, Cosgrove DP, Xu R. Pattern of distant metastases in colorectal cancer: a SEER based study. Oncotarget 6(36), 38658-38666 (2015).

27. Sun Z, Sun Y, Tan L et al. Clinical features and prognostic factors of brain metastasis from colorectal cancer. Zhonghua Zhong Liu Za Zhi. 38(1), 63-68 (2016).

28. Sherman KL, Merkow RP, Shah AM, Wang CE, Bilimoria KY, Bentrem DJ. Assessment of advanced gastric cancer management in the United States. Ann. Surg. Oncol. 20(7), 2124-2131 (2013).

29. Sud S, Holmes J, Eblan M, Chen R, Jones E. Clinical characteristics associated with racial disparities in endometrial cancer outcomes: a surveillance, epidemiology and end results analysis. Gynecol. Oncol. 148(2), 349-356 (2018).

30. Mao W, Ma B, Huang X et al. Which treatment is best for patients with AJCC stage IV bladder cancer? Int. Urol. Nephrol. 51(7), $1145-1156$ (2019).

31. Huang TB, Zhou GC, Dong CP et al. Marital status independently predicts prostate cancer survival in men who underwent radical prostatectomy: an analysis of 95,846 individuals. Oncol. Lett. 15(4), 4737-4744 (2018).

32. Riihimaki M, Hemminki A, Fallah M et al. Metastatic sites and survival in lung cancer. Lung Cancer 86(1), 78-84 (2014).

33. Oweira H, Petrausch U, Helbling D et al. Prognostic value of site-specific extra-hepatic disease in hepatocellular carcinoma: a SEER database analysis. Expert Rev. Gastroent. 11(7), 695-701 (2017).

34. Abdel-Rahman O. Clinical correlates and prognostic value of different metastatic sites in metastatic renal cell carcinoma. Future Oncol. 13(22), 1967-1980 (2017).

35. Qiu MZ, Shi SM, Chen ZH et al. Frequency and clinicopathological features of metastasis to liver, lung, bone, and brain from gastric cancer: a SEER-based study. Cancer Med. 7(8), 3662-3672 (2018). 